\title{
SAVE THE IRREMEDIABLE TOOTH WITH AID OF HYDROXYAPATITE
}

Golmoradizadeh Ali

1. Centro Escolar University, Oral Surgery \& Endo Perio Section.

\section{CORRESPONDING AUTHOR}

Golmoradizadeh Ali

26C. Tower3.

Dansalan Garden Mandaluyong.

Manila. Philippines 1550

E-mail: ali2ph@yahoo.com

Ph: 00639154829320.

ABSTRACT: Nowadays saving the irremediable tooth under the old method has low risk success, or in some cases it is impossible. This study suggests a method that could predict a good prognosis after the operation.

This case was, a crownless upper right $2^{\text {nd }}$ premolar with a big periapical lesion that extended the periradicular area also, with initial palatal root resorption . Upon examination Chronic Preapical Periodontitis diagnosed. After RCT, the tooth was extracted, curetting and irrigation of the socket was done, fill $1 / 4$ of the socket with hydroxyapatite and reimplant the tooth, during the reimplantation adjustment of the crown to root ratio considered as well ,then was splinted to the adjacent teeth for two weeks, Antibiotic was prescribed to the patient for 7 days.

Radiographic examination after two years shows that no more lesions are seen in the periapical and periradicular area, there was no mobility, and root resorption was aborted, and the tooth was in healthy condition.

KEYWORDS: Hydroxyapatite, Reimplantation, Irremediable tooth, Root resorption, Oral surgery, Implant

INTRODUCTION: We witness teeth that are diagnosed as cases of extraction due to poor oral hygiene of the patients or the incapability of the dentist to save the tooth [2]. Because of a long necrotic stage preapical lesion may appear such as Acute and chronic periradicular periodontitis, Acute periradicular abscess, chronic suppurative periodontitis, discontinuously lamina dura, initial root resorption [8]. In this study, focuses on these particular cases and recommends a way to save the faulty teeth with the aid of hydroxyapatite in the reimplantation technique.

Tooth reimplantation is a method that usually is used for avulsed tooth or in some endodontic cases [3]. But in this study use of the reimplantation technique in non-vital tooth with any periapical consideration; that if they would be left untreated the farther problem would be caused in the oral cavity [1]. The purpose of using hydroxyapatite in this study is because of it is easy manipulation, cheap and convenient, and biocompatibility. Hydroxyapatite is widely used for a long time in the dental and medical field [1].

METHOD AND MATERIALS: In this case 43 years old female complained about a dull pain in the upper right side of her jaw for the last a year. She had a history of severe pain before and she ignored it. Clinical examination shows the upper right second premolar was crownless, with a 
big periapical lesion involving the periradicular area, with initial palatal root resorption. Upon examination Chronic Preapical Periodontitis diagnosed. Medical history of the patient shows the patient has no history of any systemic diseases and she never hospitalized. For the start 2cc of the blood of the patient was collected in laboratory and was mixed it with allograft type of the hydroxyapatite (Ceno Bone $0.5 \mathrm{cc}$ powder, $0.15-2000 \mathrm{~mm}$ ) in suitable and sterile container and waited for 30 min to allow the maximum expansion of hydroxyapatite. Now we proceeded to the surgical part of the treatment. The tooth was extracted with minimal irritation to the surrounding tissue. We used the straight elevator and forceps no150 during the extraction, afterwards curetting the socket and irrigation was made with saline solution as much as possible to remove any remaining tissue and debris and dried the area toward the end gently. Then filled $1 / 4$ of the socket with hydroxyapatite that we prepared before and inserted the tooth inside the socket and adjusted the tooth up to the ideal length, it will prevent the crown lengthening in a crownless tooth. For this purpose a pattern was used, that was made from study cast of the patient (impression and study cast was made, then guidance pattern was made with aid of rubber impression material). At the end the tooth was splinted to the nearest adjacent tooth, with the rectangular orthodontic wire $(0.48 \mathrm{~mm} \times 0.63 \mathrm{~mm}$ stainless steel), that was prepared in the patients study cast. (Size of the wire is varied to the distance between the adjacent and reimplanted tooth).

The patient was prescribed antibiotics for seven days. And follow up her with the radiographic examination every month.

RESULT: In this study monthly radiographic follow up, no more periapical and radicular lesion, was seen and the stop of root resorption was seen after six months. Bone was repaired and tooth was in a good condition in the socket with no mobility. And it will be fine for use as an abutment for any prosthetic procedures.

CONCLUSION: In this case due to acceptable condition of the tooth, the tooth was used as an abutment for fixed prosthodontic denture. After two years following up of the patient condition, radiographic and clinical examination shows that, the tooth is in a healthy condition.

DISCUSSION: The main purpose of the tooth reimplantation is prevention loss of the tooth and restores the landscape of the mouth aesthetically and functionally; tooth reimplantation commonly use for avulsed tooth [7]; but tooth reimplantation with use of some materials such as hydroxyapatite its not widely use. Hydroxyapatite is one of our major body components, comprising $60 \%$ of bone, $97 \%$ of tooth enamel and $70 \%$ of dentin. Saliva is also rich in the components of hydroxyapatite, which it supplies to the teeth to replace mineral dissolved by plaque acids, the first step towards tooth decay [9]. In this project because used of porous type hydroxyapatite, the result would be more successful and the risk of ankylosis will be minimal. At last use of the natural abutment it is our responsibility in conservative dentistry and it will be safer and more comfortable for the patients, for prevention of edentulism, bone resorption and other negative effects.

ACKNOWLEDGEMENT: First of all I want to thank God, and I am sincerely thankful to my supervisor, Dr. Maria Wanda I. Martinez, whose encouragement, guidance and support from the start to the end enabled me to develop an understanding of the subject. And also thank CentroEscolar University in helping me throughout. 
Lastly, I offer my regards and blessings to all those who supported me in any aspect during the completion of this study.

\section{REFERENCES:}

1. Myron, R.Tucker.Oral\&maxillofacial surgery .3rd edition. P.329,331

2. Peterson, Edward Ellis,James R.Hupp,Myron Tucker.Biologic Cocsideration for Osteointegration.Edwin A.McGuimphy\&Peter E.Larson. Oral\&maxillofacial surgery $.3^{\text {rd }}$ edition.(1998) p .357

3. Peterson, Edward Ellis,James R.Hupp,Myron Tucker.Wound Repair.James R.Hupp. Oral\&maxillofacial surgery . $3^{\text {rd }}$ edition (1998) p. 57

4. Galden Wagnild and Kathy Mueller.Restoration of endodontically treated tooth.Aldridge E.Wilder.JR.Pathways Of the Pulp.3rd edition. (1995) p .786

5. Neville, Damm, Allen, Bouquot.Palpal \&Periapical Disease. Neville. Oral \& Maxillofacial Pathology..(2009) p.120

6. Newman Takei Carranza.Prepration of the periodontium for restorative dentistry, preprosthetic surgery. Philip R.Melnick. Clinical Periodontology.(2006) .p.1042

7. Newman Takei Carranza.Tooth Suppoting Structures.JosephP.Fiorellini.David M.Kim,Satoshi O.Ishikwa. Clinical Periodontology (2006). P.68

8. Vinod Kapoor.Transplantation of tissues.Vinod Kapoor. Oral\&maxillofacial surgery.2nd edition.(2002) .p.498

9. Vinod Kapoor.Allogenic Grafts. Vinod Kapoor. Oral\&maxillofacial surgery.2 ${ }^{\text {nd }}$ edition.(2002) p.505

10. Vinod Kapoor.Contraindication for dental implant. Vinod Kapoor. Oral\&maxillofacial surgery.2nd edition..(2002) p.576

11. Vinod Kapoor.complication in oral surgery. Vinod Kapoor. Oral\&maxillofacial surgery. $2^{\text {nd }}$ edition.(2002) p.623

12. Neville, Damm, Allen, Bouquot.Ankylosis.Bouguot. . Oral \& Maxillofacial Pathology.3rd edition.(2009) p. 75

13. Neville, Damm, Allen, Bouquot.Periapical Cyst.Neville. Oral \& Maxillofacial Pathology.3rd edition.(2009) p. 131

14. Anderson,Kahnberg,Pogrel.Osteointegration in Irradiation tissue.Tony Pogrel. Oral\&maxillofacial surgery.(2010) p .174

15. Anderson,Kahnberg,Pogrel.Extraction of teeth ,indication for extraction.Tony Pegrel . Oral\&maxillofacial surgery..(2010) p. 181

16. Anderson,Kahnberg,Pogrel.Autotransplantation of the teeth.Tony Pogrel. Oral\&maxillofacial surgery.(2010) p .286

17. Baldissera Ede F, Fontanella VR, Ito W, PomarF www. ncbi.nlm.nih.gov/pubmed(2007) 


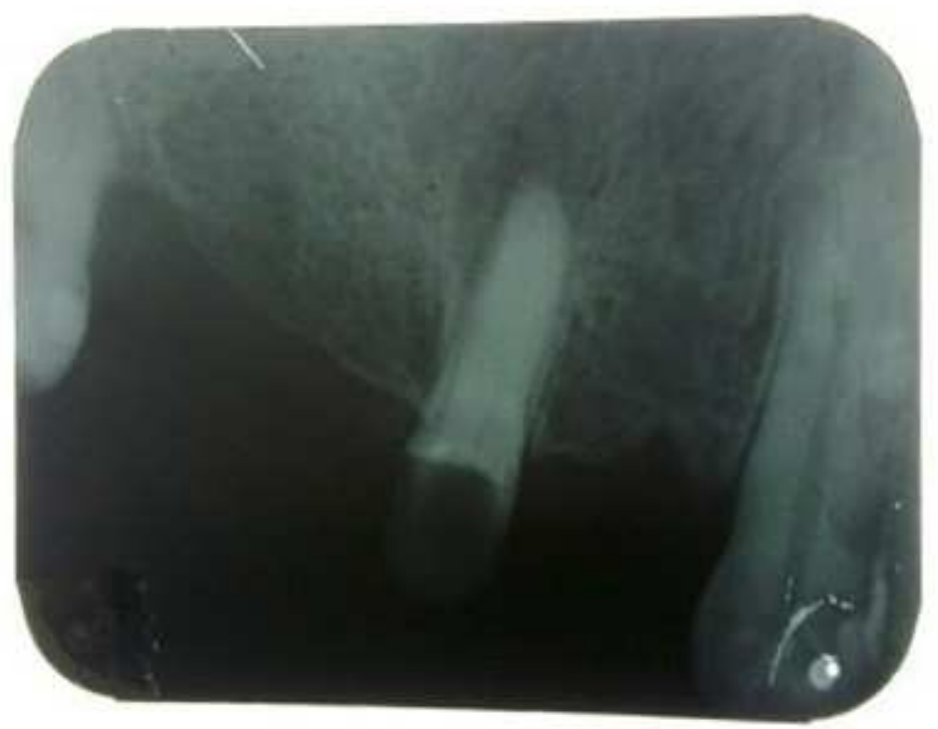

Before

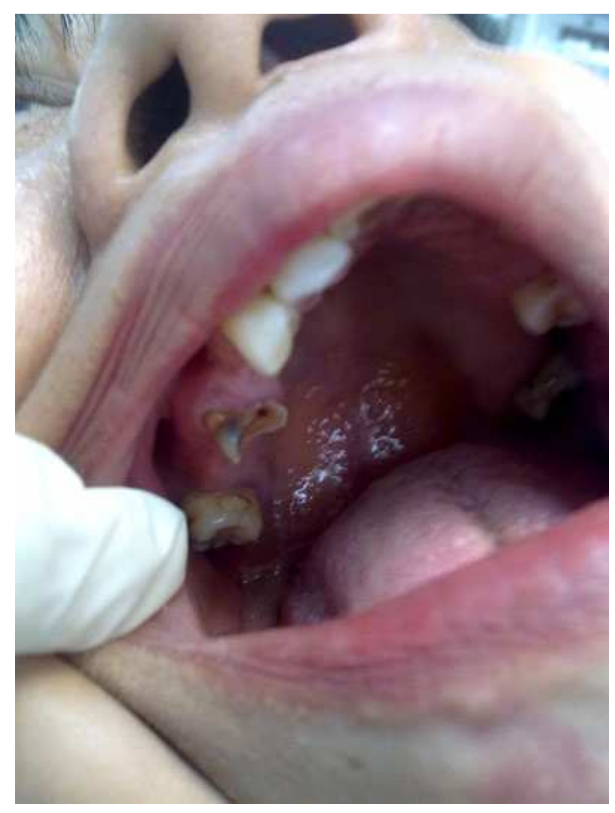

Before 


\section{CASE REPORT}

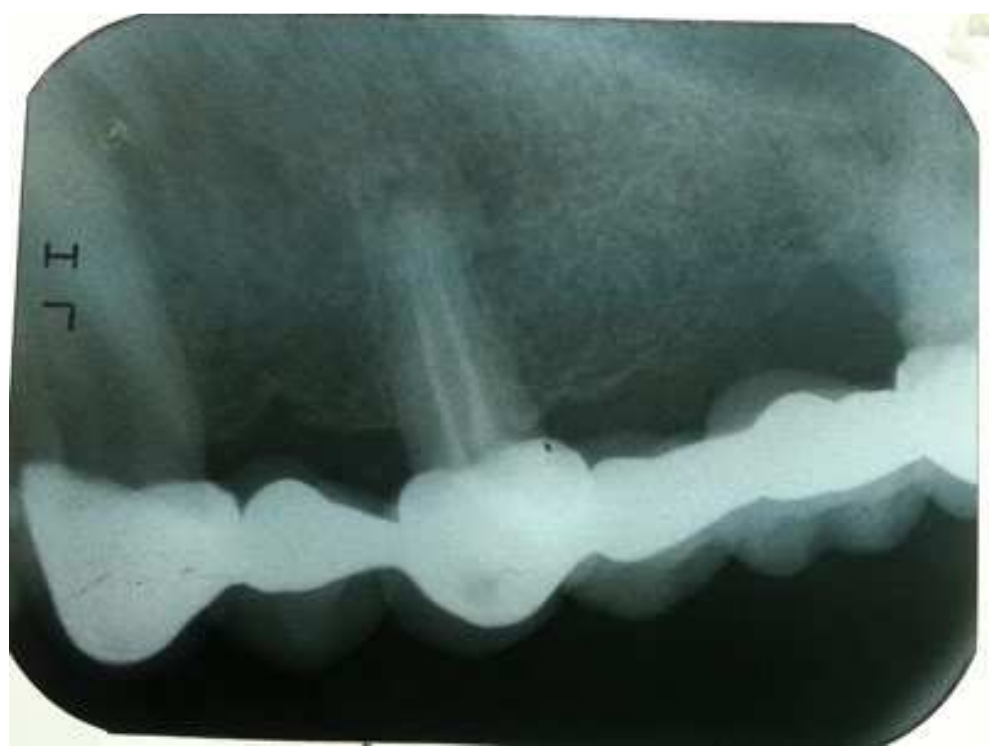

After

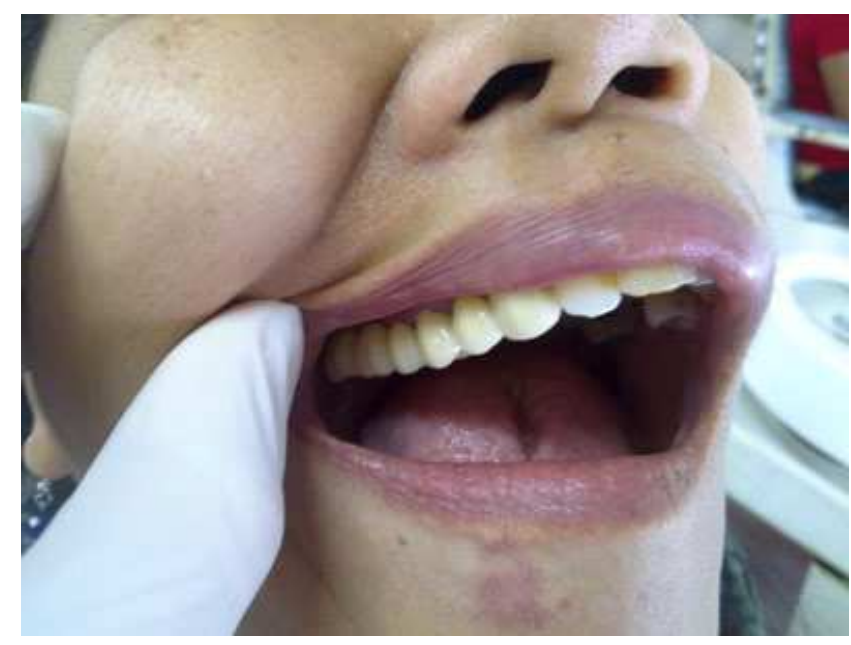

After 